\title{
Postirradiation Spinal Root Cavernoma
}

\author{
Pierre Labauge $^{\mathrm{a}}$ Anne Lefloch $^{\mathrm{a}}$ Françoise Chapon ${ }^{\mathrm{b}}$ Giovanni Castelnovo ${ }^{\mathrm{a}}$ \\ Antoine Maubon ${ }^{c}$ Valerie Rigaud ${ }^{d}$ François Segnarbieux ${ }^{e}$ \\ ${ }^{a}$ Department of Neurology, CHU de Nîmes, Nîmes, ${ }^{b}$ Department of Neuropathology, CHU de Caen, Caen, \\ ${ }^{\mathrm{C}}$ Department of Radiology, CHU de Limoges, Limoges, Departments of ${ }^{\mathrm{d}}$ Neuropathology and ${ }^{\mathrm{e}}$ Neurosurgery, \\ CHU de Montpellier, Montpellier, France
}

Dear Sir,

The consequences of radiotherapy on the spinal cord have been well known for several years [1]. They include acute myelopathy corresponding to spinal cord infarction, mild sensory myelopathy occurring several months after irradiation, chronic progressive myelopathy and lower motor neuron syndrome. The pathogenesis of the latter is not clearly established. It could be related to loss of motor neuron cell bodies or damage to cauda equina roots [1]. We report an observation of spinal root cavernoma induced by radiotherapy.

\section{Case Report}

A 52-year-old man was treated for Hodgkin's disease by radiotherapy (45 Gy over 40 sessions), with mantle and paraaortic irradiation $\left(\mathrm{T}_{10}-\mathrm{L}_{4}\right)$ in 1977. In 1995, 26 years after irradiation, he presented with painless and asymmetrical progressive weakness of the legs. Wasting, fasciculations, and distal areflexia of the legs were noted. Sensory evaluation was normal. EMG study showed decreased amplitudes of motor potentials and normal sensory potentials of the lower extremities. Cerebrospinal fluid protein concentration was increased (266 mg/dl), with normal cell counts. Neither neoplasia nor lymphoma relapse was found.
Evolution was characterized by a progressive increase in weakness and wasting of the lower extremities. Ankle and knee reflexes were abolished. Numbness, bowel, bladder or sexual dysfunction were absent.

Initial spinal MR (October 1996) showed diffuse and uniform gadolinium enhancement of the roots on $\mathrm{T}_{1}$ sequences at levels $\mathrm{L}_{1}-\mathrm{L}_{4}$. No lesion was seen on $\mathrm{T}_{1}$ sequence without contrast injection. Further MR (February 1998 and February 2003) showed an increase in the gadolinium enhancement (fig. 1a). Absence of a hypointense rim was noted on $\mathrm{T}_{2}$ sequences. Surgical biopsy of the sacral spinal nerve roots was performed to exclude malignant infiltration. The surgeon noted angiomatous aspects of the roots, without evidence of hemosiderin staining at their surface. Microscopic examination showed nerve tissue presenting fibrosis and vascular lesions. Fibrosis was observed between the nerve fibers, around and in the vessel walls. Vascular lesions were composed of closely apposed dilated cavities without intervening nerve tissue (fig. 1b). The walls of cavities were thin, with endothelium and connective tissue. Low numbers of macrophages are seen scattered around the vessel walls. These features are characteristic of cavernous malformations.

\section{Discussion}

Postirradiation spinal cord complications have been described for many years $[1,2]$. They are characterized by the occurrence of weakness many years after irradiation. Neurological symptoms consist of weakness, initially unilateral or asymmetrical, with inconstant sensory or sphincter involvement. The evolution can be variable, with stability, increase or decrease in the weakness.

Lesions can be situated in the roots, anterior or posterior, or intramedullary. Alteration of the motor potential and $F$ waves, respect of sensory potentials on electrophysiological examination argue in favor of anterior horn lesions. Anterior root gadolinium enhancement on $\mathrm{MR}$ confirms this location [1].

Many types of histological lesion have been described: demyelination with axonal lesions of the roots and chromatolysis of anterior horn cells [2]; dilated vascular channels with thickened hyalinized walls [1]. These vascular lesions predominate in small-sized vessels of the cauda equina, sparing large arteries.

In our case, histological findings were characterized by abnormal vascular cavities, without intervening nerve structures. These findings are characteristic of cavernomas and are similar to case 6 reported

\section{KARGER}

Fax +4161306 1234 E-Mail karger@karger.ch www.karger.com
(C) 2006 S. Karger AG, Base 0014-3022/06/0564-0256\$23.50/0

Accessible online at: www.karger.com/ene
Prof. Pierre Labauge

Service de Neurologie, CHU Montpellier-Nîmes

Hôpital Caremeau, 2 Avenue du Pr Debré

FR-30029 Nîmes Cedex 4 (France)

Tel. +33 46668 3261, Fax +33 46668 4016, E-Mail labauge@yahoo.fr 


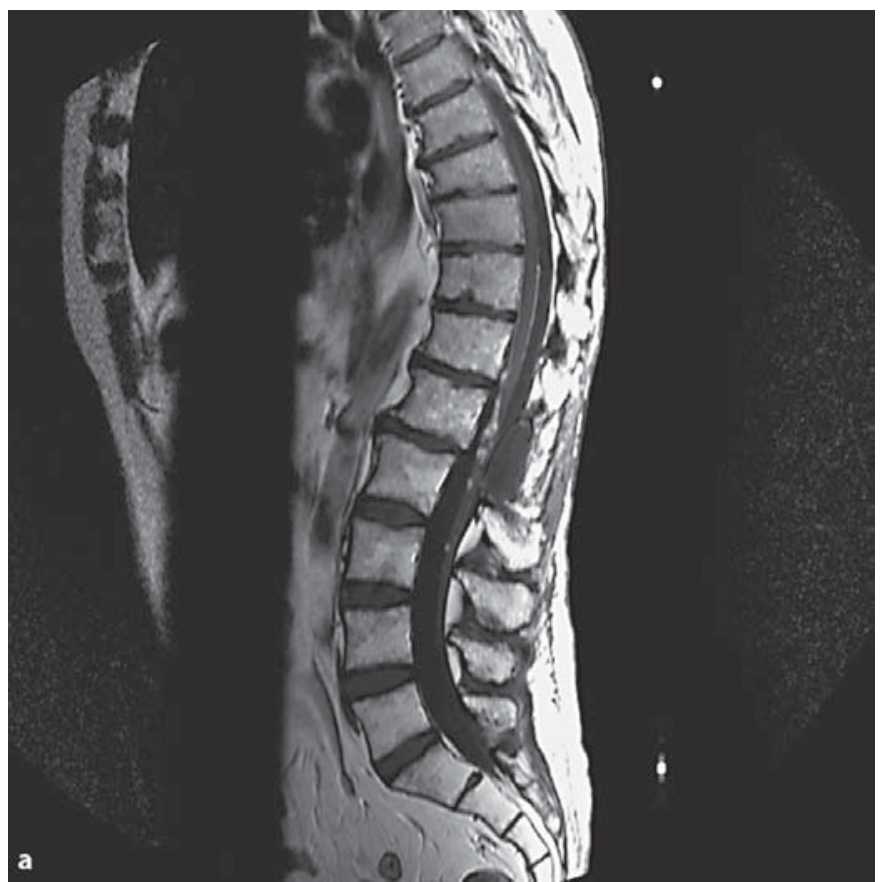

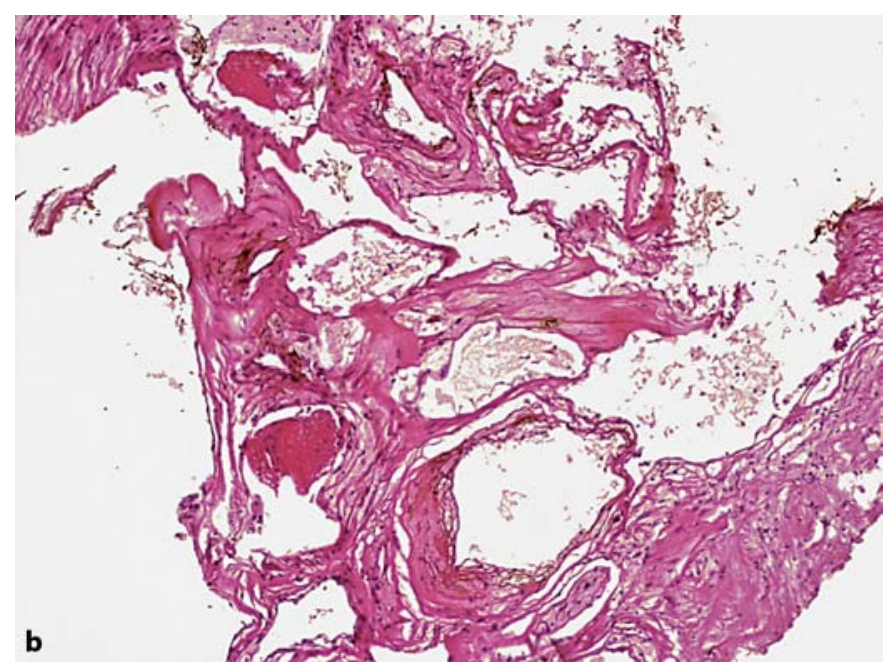

Fig. 1. a Spinal MR. T1 sequences. February 2003. Uniform gadolinium enhancement. b Hematein-eosin $\times 10$. Juxtaposition of vascular cavities with thin walls. by Bowen et al. [1]. Postradiation cavernomas have been described mainly in children following brain irradiation [3]. Occurrence of these lesions was explained by a high sensibility of the pediatric brain to radiation. Clinical and radiological evolution of these lesions are the same as spontaneous brain cavernomas. To our knowledge, 4 radiation-related spinal cord cavernomas have been reported in the literature [4-7]. They were intramedullary, with an MR aspect similar to the one of spontaneous cavernomas, i.e. hypo- and hyperintense signal on MRI, with a surrounding rim of hypointense signal on $\mathrm{T}_{2}$ sequences, without any gadolinium enhancement [46]. Postradiotherapy cavernomas were also observed in the roots, with a different MR pattern (isointense on $T_{1}$ sequences, absence of a hypointense rim on $\mathrm{T}_{2}$, pronounced gadolinium enhancement) [our case and 7]. In a postirradiation context, these radiological appearance could suggest spinal metastasis.
Common histological findings are shared by spontaneous and postirradiation cavernomas, with enlarged vascular cavities without any intervening nerve. Some histological particularities of postradiation cavernomas have been noted, including minimal collagen supports and 'back-to-back' cavernomas, absence of long-standing changes (calcifications, organized thrombi) [3]. Interestingly, postradiation arteriovenous angiomas have not been described yet.

The explanation for the formation of these lesions is unclear. Irradiation could decrease artery smooth muscular cells, with hyalinization and fibrinoid necrosis, resulting in dilatation of the vascular endothelium and formation of cavernous angiomas. Radiation could form true de novo cavernomas or enlarge asymptomatic and MR-undetectable preexisting lesions. Radiotherapy could also induce DNA damage and somatic mutations in genes predisposing to cavernomas.

\section{References}

1 Bowen J, Gregory R, Squier M, Donaghy M: The post-irradiation lower motor neuron syndrome: neuronopathy or radiculopathy? Brain 1996;119:1429-1439.

2 Berlit P, Schwechheimer K: Neuropathological findings in radiation myelopathy of the lumbosacral cord. Eur Neurol 1987;27:2934.

3 Pozzati E, Giangaspero F, Marliani F, Acciari $\mathrm{N}$ : Occult cerebrovascular malformations after irradiation. Neurosurgery 1996;39: 677-684.

4 Maraire JN, Abdulrauf SI, Berger S, Knisely J, Awas IA: De novo development of a cavernous malformation of the spinal cord following spinal axis radiation. J Neurosurg 1999;90:234-238.

5 Narayan P, Barrow DL: Intramedullary spinal cavernous malformations following spinal irradiation. Case report and review of the literature. J Neurosurg 2003;98:68-72.

6 Yoshino M, Morita A, Shibahara J, Kirino T: Radiation-induced spinal cord cavernous malformation. Case report. J Neurosurg 2005;102:101-104.

7 Jabbour P, Gault J, Murk SE, Awad IA: Multiple spinal cavernous malformations with atypical phenotype after prior irradiation: case report. Neurosurgery 2004;55:14351439. 